\title{
MULTILOCATIONAL EVALUATION OF WHITE YAM GENOTYPES USING GGE BI-PLOT METHODOLOGY
}

EMMANUEL, C. NWACHUKWU.

(Received 13 June 2013; Revision Accepted 17 July 2013)

\begin{abstract}
Yams are cultivated in diverse agroecologies and there is evidence of strong genotype and environment interaction. This has necessitated the evaluation of new yam genotypes in multi-locational trials. Five new white yam genotypes were evaluated in different locations of major yam producing areas; Umudike, Nsukka, Ubiaja, Abuja and Katsina-Ala, to test the performance and stability of these genotypes across the environments using GGE bi-plot software. The GGE bi-plot generated several graphic bi-plots which showed Umudike, Nsukka, Ubiaja and Katsina-Ala as belonging to one mega - environment while Abuja and Ubiaja belong to another. The GGE bi-plot also showed the discriminating and non-discriminating environments. Katsina-Ala was the most discriminating environment while Nsukka was the least. A test environment that lacks discriminating ability lacks the capacity to provide information about the genotype being used. Such environment lacks usefulness and should be discarded as a test environment. Katsina-Ala, with the longest vector is the most discriminating. This is followed by Ubiaja, Umudike and Abuja in that order. Nsukka is the least discriminating.
\end{abstract}

KEYWORDS: Yams, multi-environment trial. GGE biplot, mega-enviroments.

\section{INTRODUCTION}

The yams are important food crop in Nigeria supplying many with cheap caloric-energy food form. Among the yams, the white yam, Dioscorea rotundata is the most widely cultivated and is believed to be indigenous to West Africa, probably from the forest zone of south Eastern Nigeria (Onwueme, 1978).

The white yam is cultivated across diverse ecologies. However, studies by Egesi and Asiedu, (2002) and Nwachukwu et al (2006) have shown the existence of strong genotype by environment interaction (GEI) in the yams. GEl reduces the correlation between phenotype and genotype values resulting in inconsistent performance of genotypes in different environments. This condition makes the job of a breeder difficult because no genotype is consistently superior in all environments. To arrive at reasonably sound result therefore, genotypes will have to be tested in many diverse environments.

The aim of any mult-environment yield trial (MET) is to access adaptation as well as yield stability of the genotypes across the environments. However, environmental analysis to determine the adequacy of the environments is grossly neglected. Thus MET in used to evaluate genotypes as well as evaluate the test environments.

Test environment evaluation involves several aspects. The first aspect is to see if the target region or agro-ecology belongs to a single mega-environment or consists of different mega-environments. The second aspect is to identify better test environments and the third aspect is to identify redundant test locations/environments that do not supply additional information about the cultivar.

The GGE bi-plot methodology: genotype main effect (G), plus genotype by environment interaction (GE) of yam (2001), is a very powerful tool for such environmental analysis. This paper therefore describes the use of GGE bi-plot methodology in the evaluation of test environments in a multi-environment trial of six white yam genotypes tested across five locations.

\section{MATERIALS AND METHOD}

Five white yam hybrid genotypes, DRN100/1/1, DRN150/2/001, DRN200/4/2, DRN95/79/2 and DRNM 2 $/ 50 / 5$ were used in the trial. The locations, representing diverse but distinct agro-ecologies in the Nigerian yam belt where the trial was conducted were Umudike, Nsukka, Kastina-Ala, Ubiaja and Abuja. In each location, the local best white yam cultivar was used as check. In Umudike, Nsukka, Ubiaja and Abuja, the check cultivar was Obiaoturugo, while the local best used as check in Kastina-Ala was Ogoja. However, during data analysis and reporting, they were collectively referred to as checks.

The hybrid genotypes were planted out in the locations in a randomised complete block design and replicated three times. In all the locations, planting was done in 2011 and repeated in 2012 seasons. Planting was done when the rainy season had stabilized (MayJune) at each location in both years under rainfed conditions.

The average sett size of the planting materials was $200 \mathrm{~g}$. Each plot contained 20 plants planted in a plot size of $5 \mathrm{~m} \times 4 \mathrm{~m}$ with an inter-plant spacing of $1 \mathrm{~m}$. The cultural practice was as recommended for wareyam cultivation (Onwueme, 1978). Yield data was collected and expressed as tuber yield per stand in $\mathrm{kg}$. The data was analysed using the GGE biplot software (Yan, 2001).

Emmanuel, C. Nwachukwu. National Root Crops Research Institute, Umudike, PMB 7006, Umuahia, Abia State, Nigeria. 


\section{RESULTS AND DISCUSSION}

The GGE bi-plot generated several graphic bi-plots and the bi-plots explained $87.3 \%$ of the total variations. Fig.1. visualizes locations and the genotypes that performed best in them. From the bi-plot, a polygon drawn from entries (genotypes $M_{2} / 50 / 5,100 / 1 / 1$, and check) located away from the bi-plot origin such that all other entries, 95/79/2,200/4/2 150/2/001 are contained within the polygon and a line, drawn from the origin of the bi-plot and perpendicular to the sides of the polygon (in this case a triangle) effectively divided the bi-plot into three sectors: the $M_{2} / 50 / 5$ vertex sector, the 100/1/1 vertex sector and the check vertex sector (Yan and Kang, 2003). Thus, $M_{2} / 50 / 5$ and 200/4/2 performed best in Umudike, Nsukka and Katsina-Ala locations while 100/1/1 and 150/2/001 performed best in Abuja and Ubiaja locations. The check materials and 95/79/2 did not seem to have performed well in any of the locations. Also, from the bi-plot, two mega environments were suggested with Ubiaja and Abuja forming one mega environment and Umudike, Nsukka and Katsina-Ala forming the other mega environment. These locations, Abuja and Ubiaja and Umudike, Nsukka and Katsina-Ala fell into distinct sectors, thus meeting one of the conditions for the existence of mega environments (Gauch and Zobel, 1997). Graphically, different megaenvironment should consist of groups of test environments that are apparently separated in a biplot.

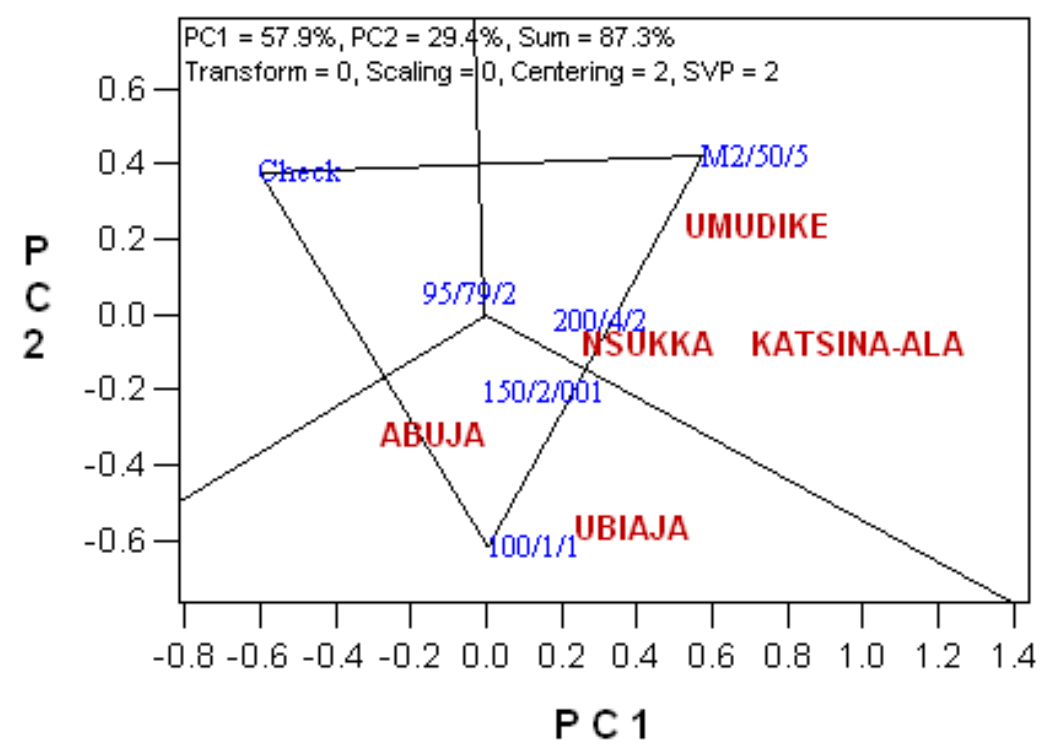

Fig. 1: Which clone won where and mega-environments.

Fig.2, referred to as the vector view of the GGE biplot, (Yan and Kang, 2003) is describing the discriminativeness and the representativeness of the test environments. The environments are connected with the bi-plot origin via lines called vectors. The length of these environment vectors represent the measure of their discriminating ability, thus longer vectors have greater discriminating ability while short vector lengths indicate lesser discriminating ability. A test environment that lacks discriminating ability provides no information about the cultivars being tested and therefore, such an environment is not very useful and should be discarded as a test environment (non-discriminating environment). From the bi-plot therefore, Katisna-Ala, with the longest vector is the most discriminating. This is followed by Ubiaja, Umudike, and Abuja in that order. Nsukka happens to be the least in discriminating ability. 


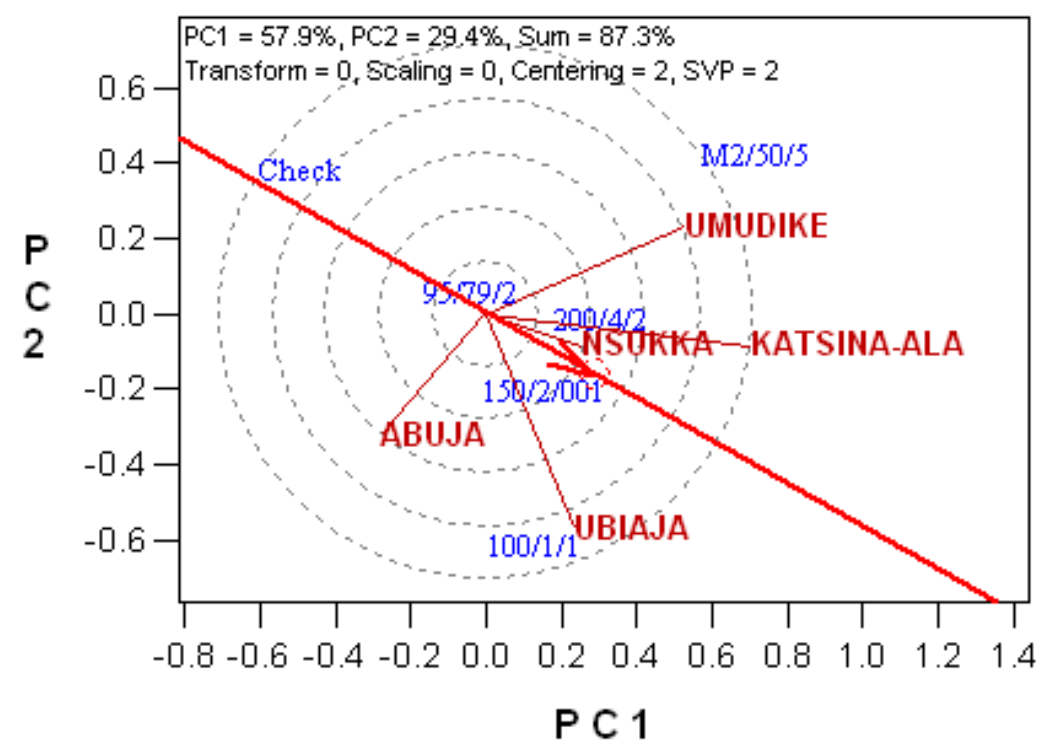

Fig.2:Discrimitiveness $v$ s. representativenss of locations

\section{REFERENCES}

Egesi, N. C and Asiedu, R., 2002. Analysis of yam yield using additive main effects and multiplicative interaction (AMMI) model. African crop Sci. 5, (10): 195-201.

Gauch, H. G and Zobel, R. W., 1997. Identifying megaenvironments and targeting genotypes. Crop Sci. (37): 311-326.

Nwachukwu, E. C., Ikeorgu, J. E. G and Asiedu, R., 2006. Proc. $31^{\text {st }}$ Ann. Conf. Genetics Soc. Nigeria, 6-9 Nov. 2006. Ibadan. 24-28.
Onwueme, I. C., 1978. The tropical tuber-crops. Yams, cassava, sweet-potato and coco yams. John Wiley and Sons, New York. pp 234.

Yan, W., 2001. GGE Biplot-a windows application for graphical analysis of multi-environment trial data and other types of two-way data. Agron. J. (93): 1111-1118.

Yan, W and Kang, M. S., 2003. GGE biplot analysis. A graphical tool for Breeders, geneticists, and agronomists. CRC Press, LLC. Boca Roton, Florida. 271. 